\title{
Influence of Residual Stress on Fatigue Design of AISI 304 Stainless Steel
}

\author{
L. Singh*a, R.A. Khan ${ }^{\mathrm{b}}$ and M.L. Aggarwala \\ ${ }^{*}$ a Mechanical Engineering Department, YMCA Institute of Engineering, Faridabad -121006, Haryana, India. \\ bMechanical Engineering Department, Jamia Millia Islamia, New Delhi-110025.
}

Received 5 August 2009; accepted 14 February 2010

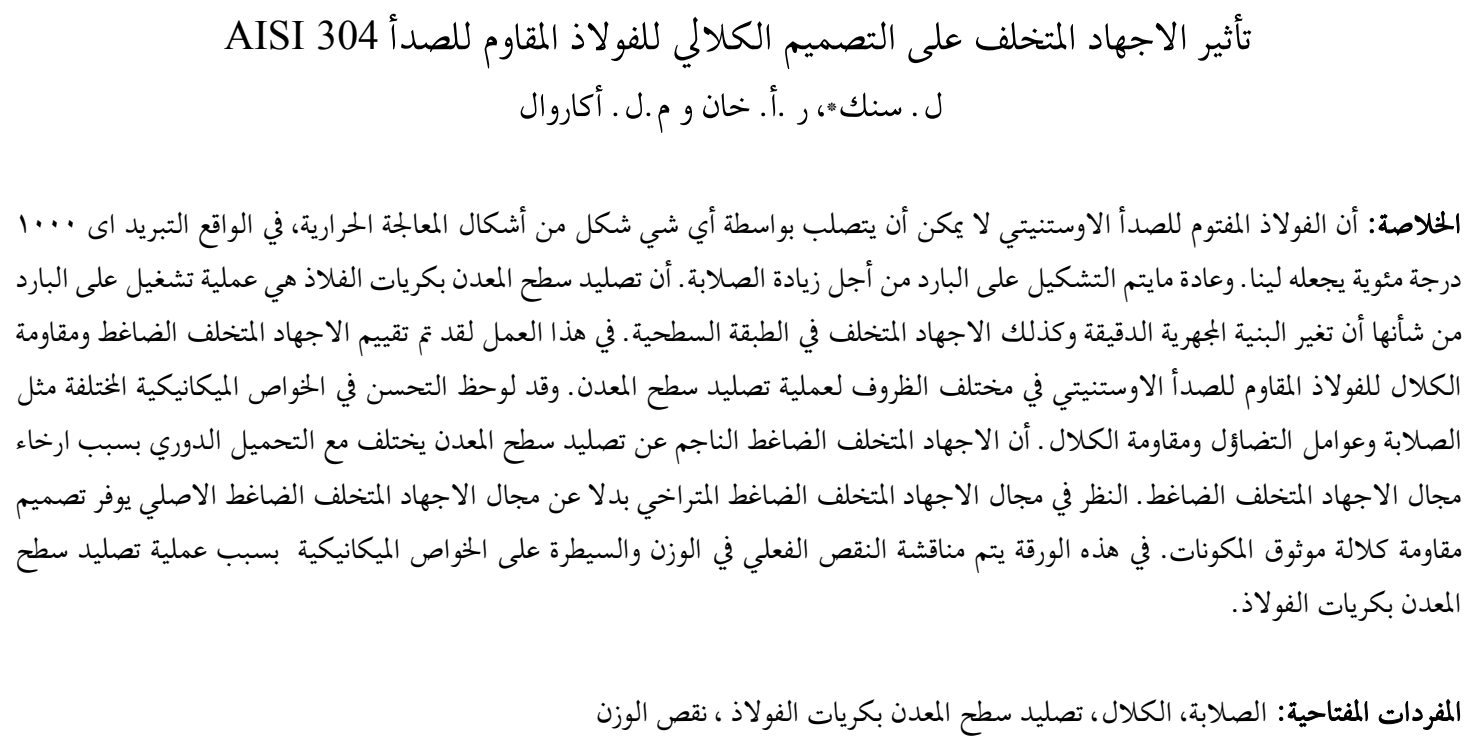

\begin{abstract}
Austenitic stainless steel cannot be hardened by any form of heat treatment, in fact, quenching from $10000 \mathrm{C}$ merely softens them. They are usually cold worked to increase the hardness. Shot peening is a cold working process that changes micro-structure as well as residual stress in the surface layer. In the present work, the compressive residual stress and fatigue strength of AISI 304 austenitic stainless steel have been evaluated at various shot peening conditions. The improvement in various mechanical properties such as hardness, damping factors and fatigue strength was noticed. Compressive residual stress induced by shot peening varies with cyclic loading due to relaxation of compressive residual stress field. The consideration of relaxed compressive residual stress field instead of original compressive residual stress field provides reliable fatigue design of components. In this paper, the exact reductions in weight and control of mechanical properties due to shot peening process are discussed.
\end{abstract}

Keywords: Hardness, Fatigue, Shot peening, Weight reduction

\section{Nomenclature}

$\begin{array}{ll}\text { CRSF } & \text { compressive residual stress field } \\ \text { RCRSF } & \text { relaxed compressive residual stress field } \\ \mathrm{A} & \text { Almen 'A' scale } \\ \mathrm{S}_{\mathrm{y}} & \text { yield point stress } \\ \mathrm{S}_{\mathrm{sp}} & \text { permissible stress } \\ \mathrm{S}_{\mathrm{sp}} / & \text { permissible stress after shot peening } \\ \mathrm{FOS} & \text { factor of safety } \\ \mathrm{P} & \text { applied load at the spring end }\end{array}$

*Corresponding author's e-mail: lakhwinder_ymca@hot mail.com 


$\begin{array}{ll}\mathrm{L} & \text { half the length of span } \\ \mathrm{N} & \text { total number of leaves } \\ \mathrm{B} & \text { width of each leaf } \\ \mathrm{T} & \text { the thickness of the each leaf } \\ \mathrm{L}_{\mathrm{T}} & \text { total length of the leaf spring } \\ \rho & \text { density of leaf spring material. }\end{array}$

\section{Introduction}

Shot Peening is a method of cold working in which compressive stresses are induced in the exposed surface layers of metallic parts by the impingement of a stream of shots directed at the metal surface at high velocity under controlled conditions. The major applications are related to improvement and restoration of fatigue life and reliability of machine elements by increasing their fatigue strength, straightening and forming of machine elements (metal parts), pretreatment prior to plating, pretreatment for components to be metalized or coated with plastics, enhancement to resistance to stress corrosion cracking and corrosion fatigue, etc. Shot peening improves the fatigue and abrasion resistance of metal parts. Very fine cracks are generated in plastically deformed layer by shot peening. Existing dislocations are interacting with these dislocations in the deformed zone and results in no sharp slip steps. This effect leads to homogeneous deform surface zone and therefore leads to retardation of crack initiation (Pandey and Deshmukh, 2001). It is applicable to ferrous and non-ferrous parts but is mostly used on steel surfaces. It consists of throwing hardened steel balls at the surface to be peened. The steel balls, or shots, are thrown against the surface either by compressed air or by centrifugal force as rotating wheel fires the shot. The intensity of the process can be varied by regulating the size of shot, the hardness of shot, speed at which it is fired, the length of time and the work is exposed to the shot. The result of the interaction of material parameters with the shot peening parameters are generation of residual stresses, strain hardening of the surface and sub surface layers, changes in microstructure and substructure of material, change in surface conditions and hardening characteristics of the material.

Mitsubayashi, et al. 1995, suggested a method of improvement in fatigue strength by shot peening and selection of most effective peening condition. Shaw, et al. 2003, illustrated the role of residual stress on the fatigue strength of high performance gearing. Aggarwal, et al. 2005 and Aggarwal, 2006 found that the controlled shot peening improves hardness, causes relaxation of residual stress and increases fatigue strength of EN45A spring steel.
Austenitic stainless steel cannot be hardened by any form of heat treatment, in fact, quenching from $1000^{\circ} \mathrm{C}$ merely softens them (Devdutt and Aggarwal, 2006). In the present work, the exact reductions in weight due to relaxation of residual stress and control of mechanical properties by shot peening, are discussed for AISI 304 stainless steel.

\section{Experimental Procedure}

The chemical composition of austenitic stainless steel AISI 304 used was shown in Table 1. The mechanical properties of parent material are: yield strength $210 \mathrm{MPa}$, ultimate tensile strength $560 \mathrm{MPa}$, fatigue limit $176 \mathrm{MPa}$ and elongation $40 \%$. The specimens were made according to ASTM standards. The specimen used for determining the fatigue strength is shown in Fig 1. Some specimens were shot peened for the purpose of comparing the peening effect. A-type Almen strip, 76X19X1.3mm thick was used to measure the intensity of shot peening.

$\begin{array}{lll}W / T & = & 2 \text { to } 6 \\ \mathrm{~L} & \geq & 3 \mathrm{~W} \\ \mathrm{R} & \geq & 8 \mathrm{~W} \text { to minimize } \mathrm{K}_{\mathrm{t}} \text { of } \\ & & \text { specimens } \\ \text { Taking, } \mathrm{T} & = & 5 \mathrm{~mm} \text { (thickness of the } \\ & & \text { specimens } \\ \mathrm{W} & = & 13 \mathrm{~mm} \text { (width of specimen) } \\ \mathrm{L} & = & 42 \mathrm{~mm} \\ \mathrm{R} & = & 117 \mathrm{~mm}\end{array}$

Almen intensity was expressed as arc height of Almen strip. $0.15 \mathrm{~mm}$ camber value was designated as 6A. Shot peening was doing with centrifugal wheel system: diameter of wheel $495 \mathrm{~mm}$, operating speed $2250 \mathrm{rpm}$. The cast steel spherical shots of $0.6 \mathrm{~mm}$ diameter were used. The hardness of the shots was $56 \mathrm{HRC}$ to $60 \mathrm{HRC}$. Shot flow rate was varied to obtain various shot peening intensities. The material was treated with Almen intensities; 3A, 6A, 8A and 15A. The coverage of shot peening is $90 \%$. In fatigue test a stress ratio $(\mathrm{R})$ equal to 0.1 was used. The specimens are testing in axial fatigue testing machine MTS model 810 , at a frequency $30 \mathrm{~Hz}$, at room temperature. 
Table 1. Chemical composition of AISI 304 (wt \%)

\begin{tabular}{|c|c|c|c|c|c|c|c|c|c|c|}
\hline Steel & C & Si & Mn & P & S & Ni & Cr & Mo & V & N \\
\hline AISI304 & 0.08 & 0.65 & 3.0 & 0.042 & 0.03 & 10 & 20 & 2 & 0.14 & 0.48 \\
\hline
\end{tabular}

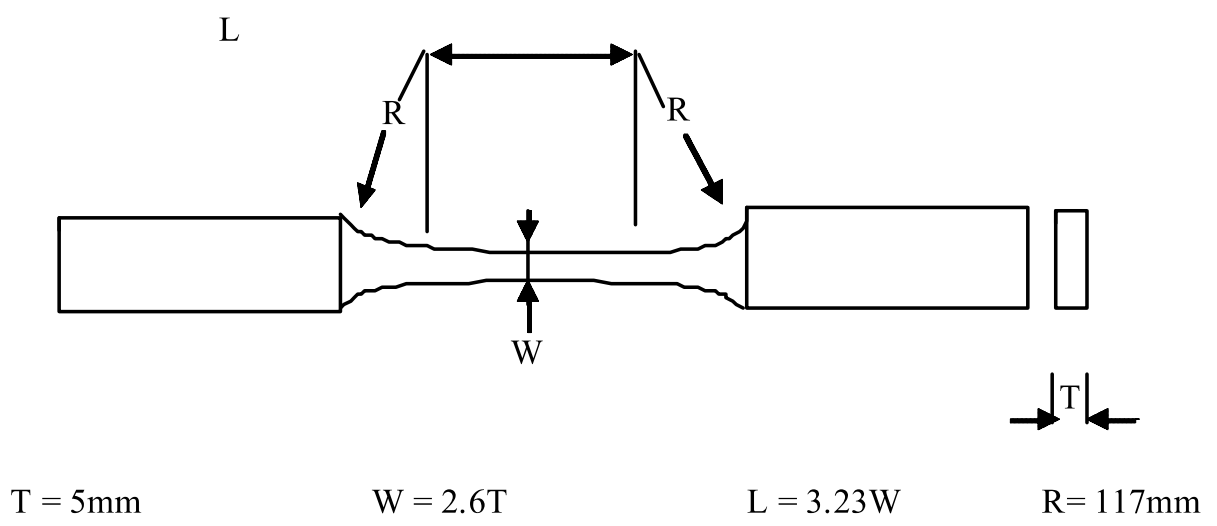

Figure 1. ASTM flat specimen for fatigue strength

The residual stress induced by shot peening was measured by X-ray diffraction method. A Cr tube operating at $30 \mathrm{kV}$ with current $8 \mathrm{~mA}$ was used for projecting $\mathrm{k} \alpha 1 \mathrm{X}$-rays. The diffraction angle $2 \theta$ without strain was taken as $135.4^{\circ}$.

\section{Fatigue Design}

Information flow diagram for improvement in fatigue design of a component is shown in Fig. 2. The essential characteristics to be known for the fatigue design are: (i) $\mathrm{S} / \mathrm{N}$ curve (ii) CRSF (iii) RCRSF. The data obtained from these characteristics and the mechanical properties of the material helps in fatigue design of the component.

Basic material data obtained on simple specimen is used for prediction model suggested by (Schijve, 2003). The various design factors should be judiciously chosen and the decision is based on data calculated, governing conditions, statistical variations and application. In laboratory testing maximum and minimum load is applied at operating frequency to ascertain whether the component will sustain the definite number of cycles or not.

\section{Results and Discussion}

Fatigue design of shot peened AISI 304 stainless steel leaf spring has been illustrated with an example. The design shows the improvement in fatigue life, fatigue strength, reduction in weight and reliability. Also the hardness of the component improves with shot peening.

\subsection{Mechanical Properties}

Three mechanical properties are discussed for reliable fatigue design of shot peened leaf springs:

\subsubsection{Hardness}

Due to shot peening treatment, the effect of change in hardness was observed in the surface layer. The average value of hardness for base material ie. un-shot peened sample (USP) was 198 HV for AISI 304 stainless steel. Depending on the shot peening intensity, the hardness varied from $242 \mathrm{HV}$ to $328 \mathrm{HV}$ for shot peened samples (Table 2). The increase in hardness was seen because of the plastic deformation of metals on the metal surface. Also after shot peening the austenite phase is partially converted into martensite phase. The microstructure of unpeened austenitic stainless steel (austenite phase) and microstructure of shot peened austenitic stainless steel (martensite + austenite phase) shown in Fig. 3 and Fig. 4. The phase transformation also improves the hardness (Goa Yukui, 2004). The effect of shot peening was limited to a very small depth, 0.25 to $0.60 \mathrm{~mm}$ from the surface. It may be noticed that the depth of deformed layer is found to vary with shot peening intensity.

\subsubsection{Damping Factor}

The damping capacity in a system is characterized by a ratio called damping ratio or damping factor. It is the ratio of damping to critical damping. Damping factor is an important surface characteristic, which varies with shot peening conditions and depth from the surface of materials (Aggarwal, 2008). Damping ratio or damping factor of shot peened sample is measured by 


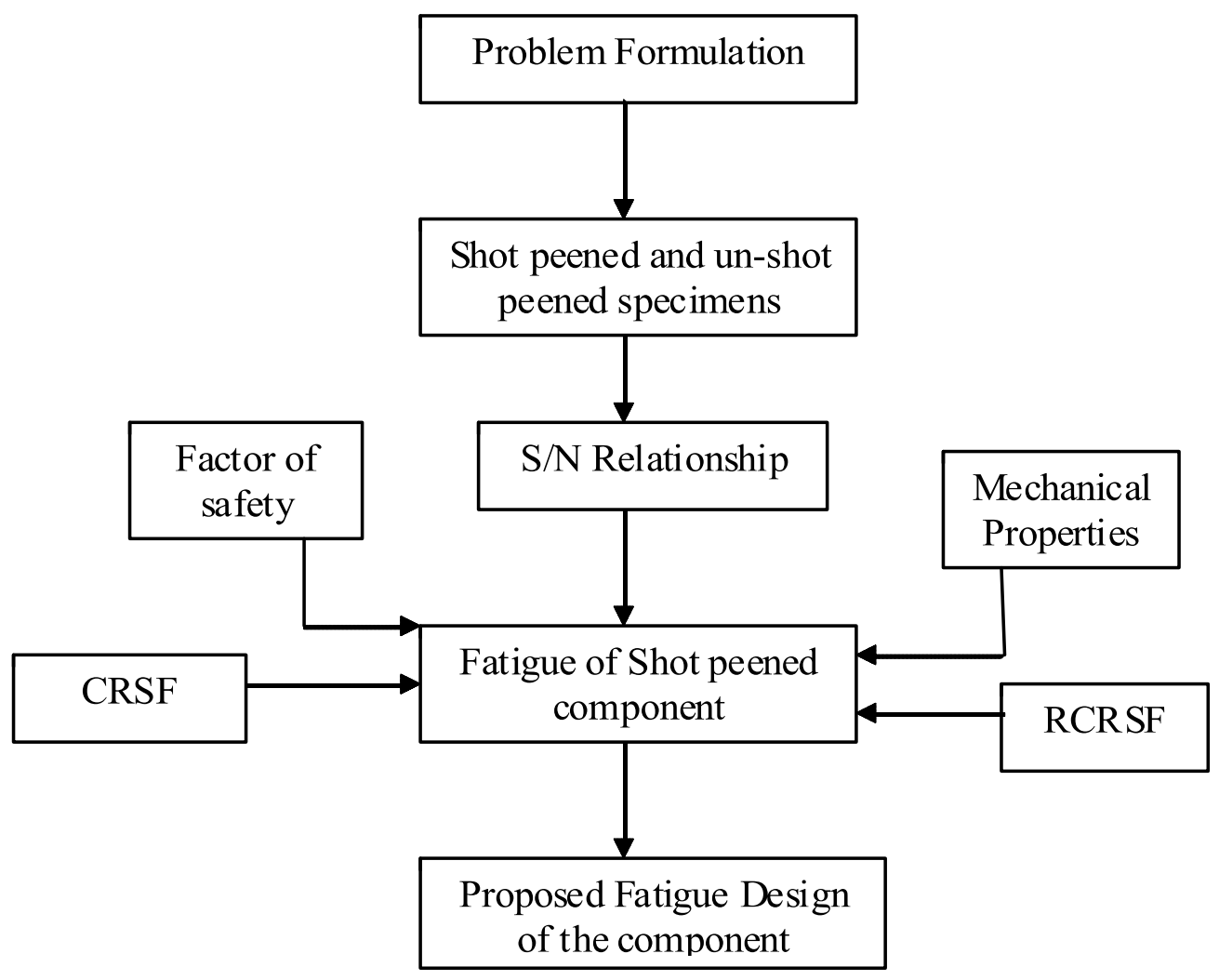

Figure 2. Flow diagram for improving design

Table 2. Variation of hardness and depth of deformed layer with shot penning

\begin{tabular}{|c|c|c|c|}
\hline S.No. & $\begin{array}{c}\text { Shot Pen ning inten sity } \\
\text { (Almen "A" scale) }\end{array}$ & $\begin{array}{c}\text { Hardness of A IS I 304 } \\
\text { stainless steel (HV) }\end{array}$ & $\begin{array}{c}\text { Depth of de for med } \\
\text { layer (m m) }\end{array}$ \\
\hline 1 & 3A & 242 & 0.25 \\
2 & $4 \mathrm{~A}$ & 273 & 0.41 \\
3 & 6A & 291 & 0.48 \\
4 & 8A & 328 & 0.60 \\
\hline
\end{tabular}

using an experimental set-up consisting of a CRO, accelerometer and amplifier. The damping factor is calculated from the logarithmic decrement $(\delta)$ (Meriam and Kraige 2002).

Damping factor is critical property of the material to control the vibrations. Table 3 shows the damping factor of un-treated sample at different depth from the surface. It was also found that with increase in depth of deform layer, damping factor increases (Table 4). This was due to the induction of compressive stress on the thin layer of the surface by changing shot peening intensity.

\subsection{S/N Curves}

Shot peeing improves the fatigue strength of the components. It repairs micro cracks and hence, the initiation of fatigue crack over the surface can be delayed by cold working of the surface with the shots (Goa et al 2003 and Sharma 2001).

$\mathrm{S}-\mathrm{N}$ curves for the base material and the shot peened specimens were determined using an axial fatigue-testing machine. The four stress levels $210 \mathrm{MPa}, 225 \mathrm{MPa}, 240 \mathrm{MPa}$ and $265 \mathrm{MPa}$ were tested and more tests were conducted near the endurance limit. Fifteen specimens (SAE Annual Book, 1977) were tested in order to plot an $\mathrm{S} / \mathrm{N}$ curve. Only the average points were presented for each level (Fig. 5). At different stress levels shot peening influence the fatigue strength. The effect of shot peening was negligible if the magnitude of the applied stress is above the endurance limit.

It is important to note that there is reduction in fatigue strength at higher Almen intensities. At Almen intensity $15 \mathrm{~A}$ fatigue strength of the specimen is less 


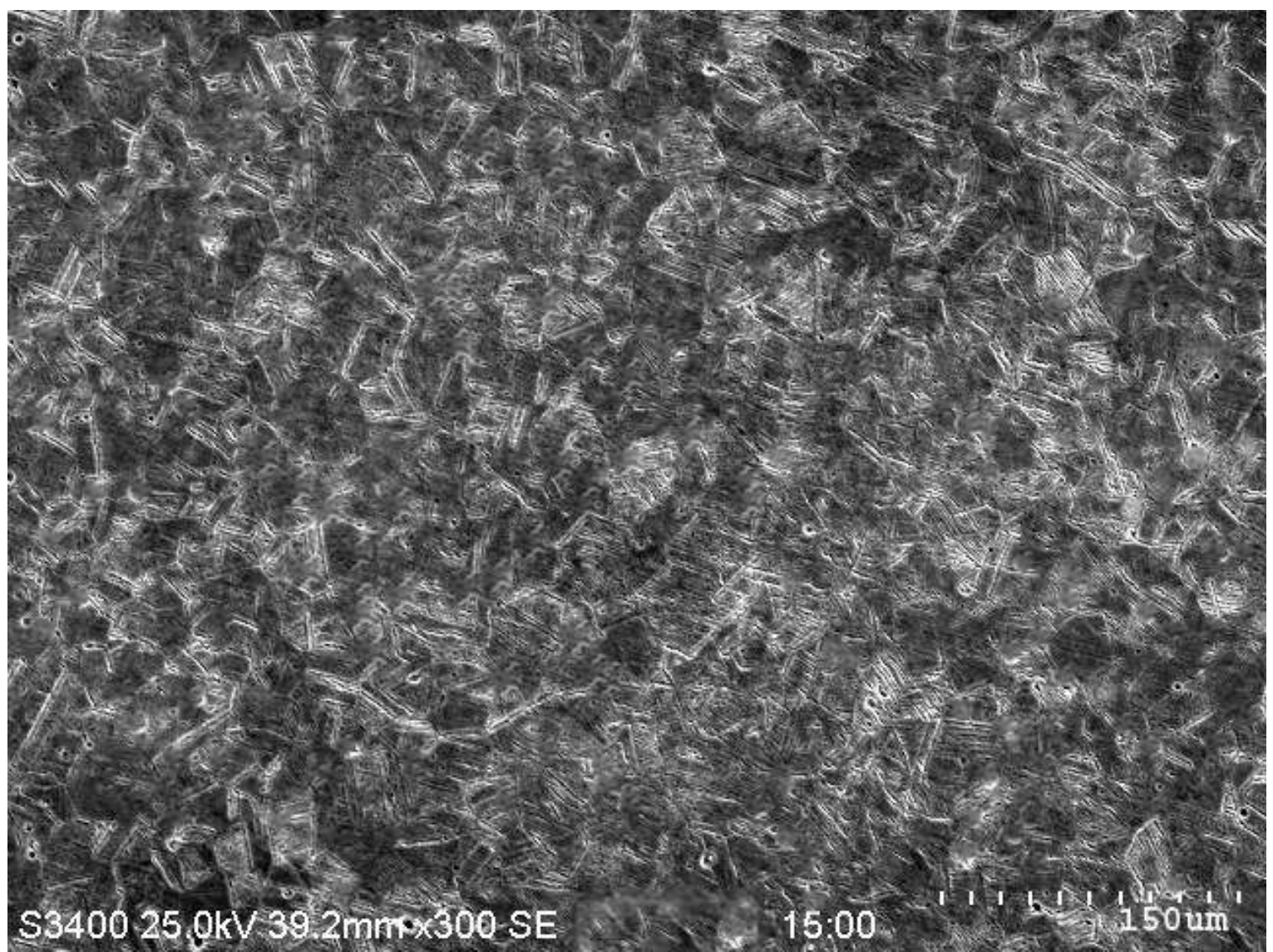

Figure 3. Microstructure of austenitic stainless steel without short peening

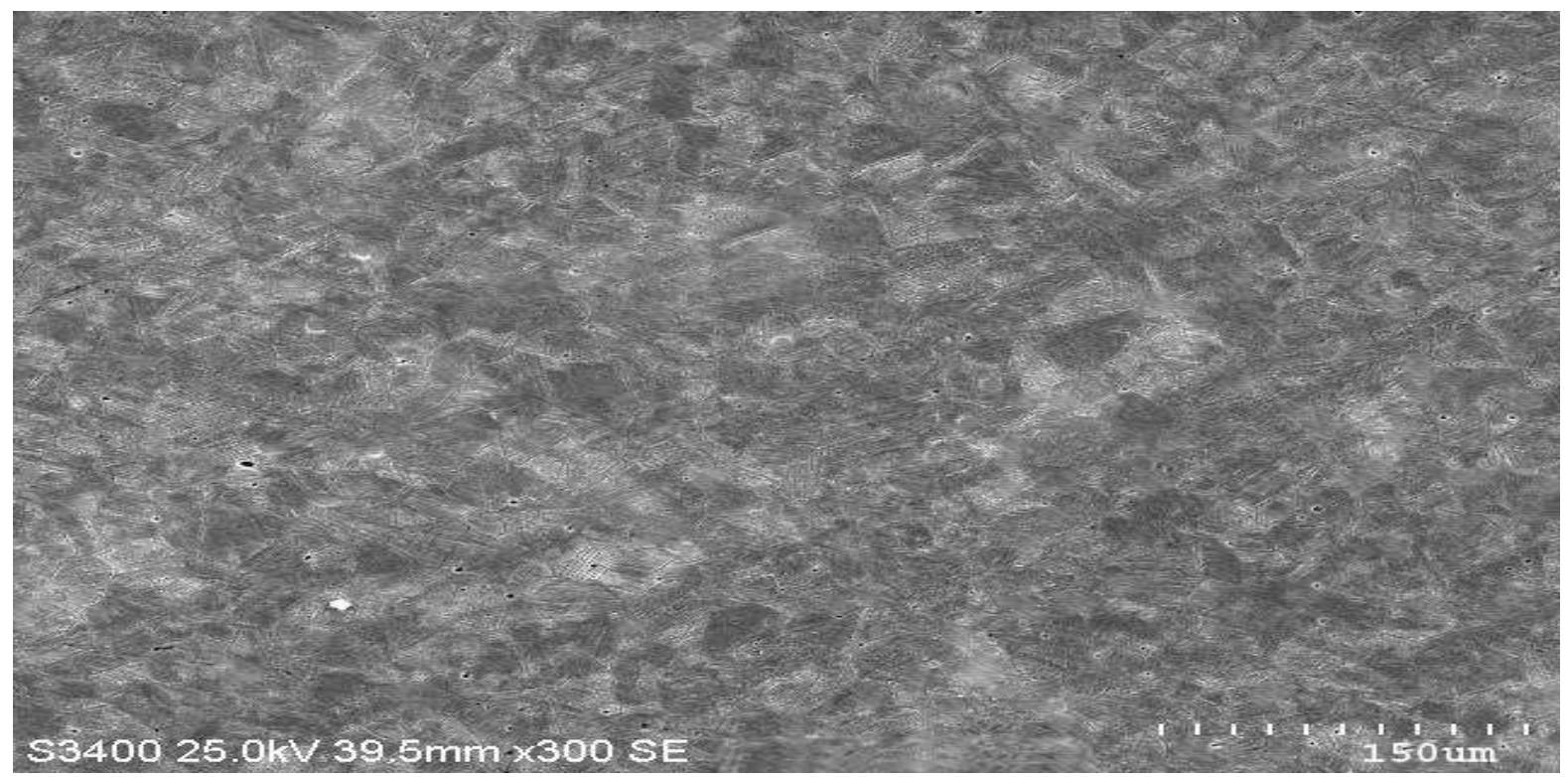

Figure 4. Microstructure of austenitic stainless steel with shot penning

as compare the Almen intensity $8 \mathrm{~A}$ (Fig. 5). This reduction in fatigue life at higher Almen intensities is due to damage of surface material, which leads to crack initiation on the surface. Hence, it is not necessary that increase in shot peening intensity will always increase fatigue strength (Goa et al. 2003).

\subsection{Reduction in Weight}

4.3.1. Compressive Residual Stress Field (CRSF)

Measurement of CRSF was carried out by X-Ray diffraction method. The measurement of residual stress with X-rays utilizes the interatomic spacing of 
Table 3. Damping factor for un-treated specimen

\begin{tabular}{|c|c|c|}
\hline $\begin{array}{c}\text { S. } \\
\text { No. }\end{array}$ & Thickness of layer removed fro m surface $(\mathbf{m} \mathbf{m})$ & Damping factor of un-treated specimen \\
\hline 1 & Nil & 0.08936 \\
\hline 2 & 0.03 & 0.07689 \\
\hline 3 & 0.06 & 0.06239 \\
\hline 4 & 0.12 & 0.06013 \\
\hline & Average & 0.07219 \\
\hline
\end{tabular}

Table 4. Effect of shot penning on damping factor

\begin{tabular}{|c|c|c|}
\hline S. No. & Thickness of layer removed from surfa ce $(\mathbf{m} \mathbf{m})$ & Damping factor of un-treated specimen \\
\hline 1 & Nil & 0.08936 \\
\hline 2 & 0.03 & 0.07689 \\
\hline 3 & 0.06 & 0.06239 \\
\hline 4 & 0.12 & 0.06013 \\
\hline & Average & 0.07219 \\
\hline
\end{tabular}

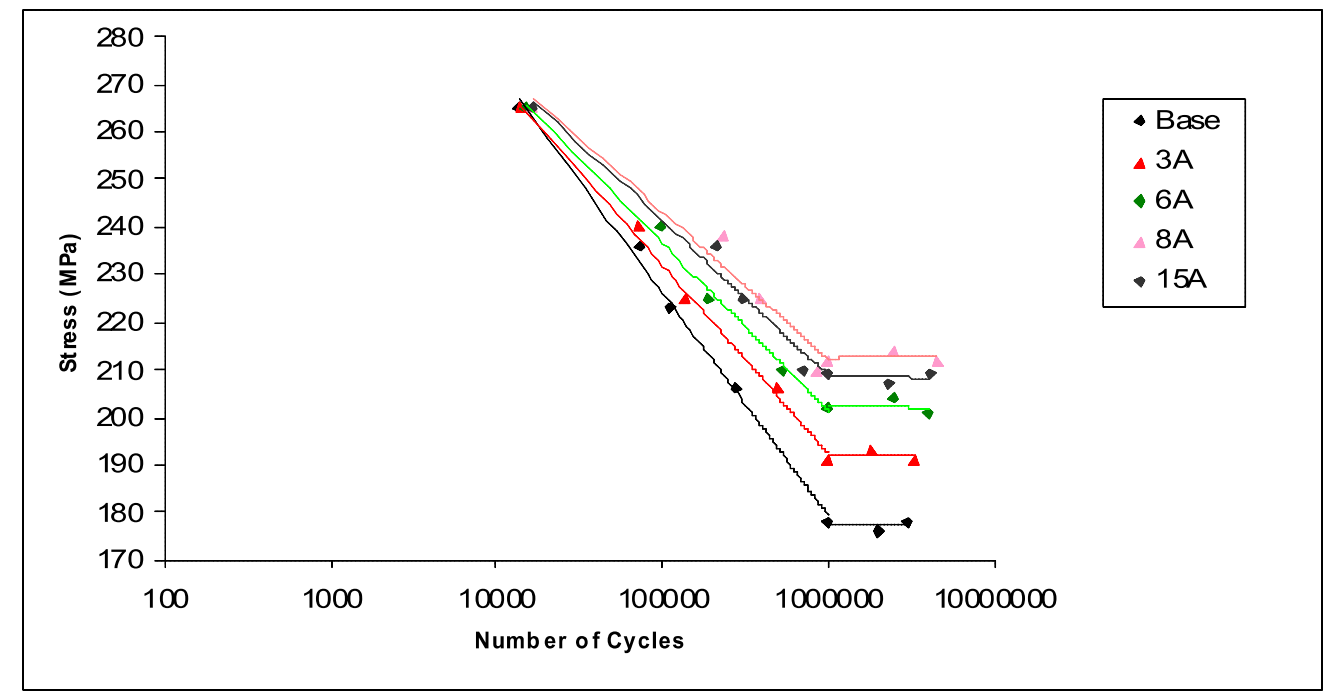

Figure 5. S/N curve of leaft spring at various shot peened intensities

certain lattice planes as the gage length for measuring strain, Fig. 6. In essence, the interatomic spacing (d) for a given lattice plane is determined for the stressfree condition and for the same material containing residual stress. The change in lattice spacing is related to residual stress. Bragg's law expresses the relationship between the distance between a give set of lattice planes (d), and the wavelength of X-ray radiation $(\lambda)$, the order of diffraction (n), and the measured diffraction angle $(\theta)$ :

$$
2 \mathrm{~d} \sin \theta=\mathrm{n} \lambda
$$

The strain normal to the surface, which is measured by X-rays:

$$
\mathrm{e}=\frac{d_{1}-d_{0}}{d_{1}}
$$

$\mathrm{e}=$ normal strain

$\mathrm{d}_{1}=$ lattice spacing with shot peening, $\mathrm{A}^{0}$

$\mathrm{d}_{0}=$ lattice spacing without shot peening, $A^{0}$

Residual compressive stress $=-\mathrm{E} \frac{d_{1}-d_{0}}{d_{1}}$ 
Incident rays

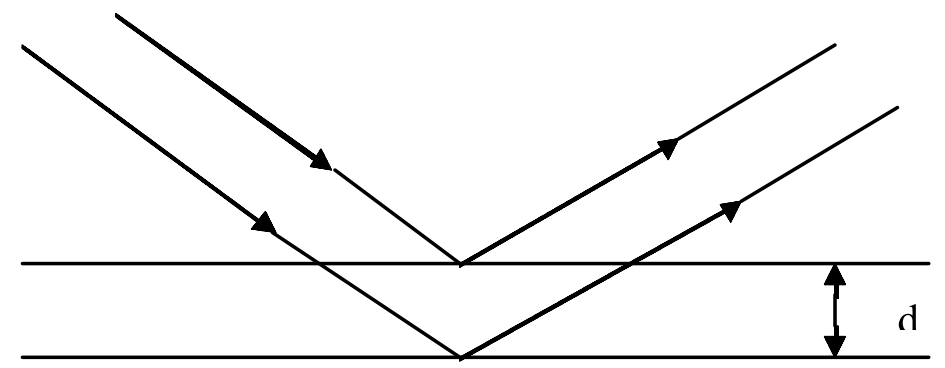

Figure 6. Reflextion of X-rays by equidistant parallel atomic planes

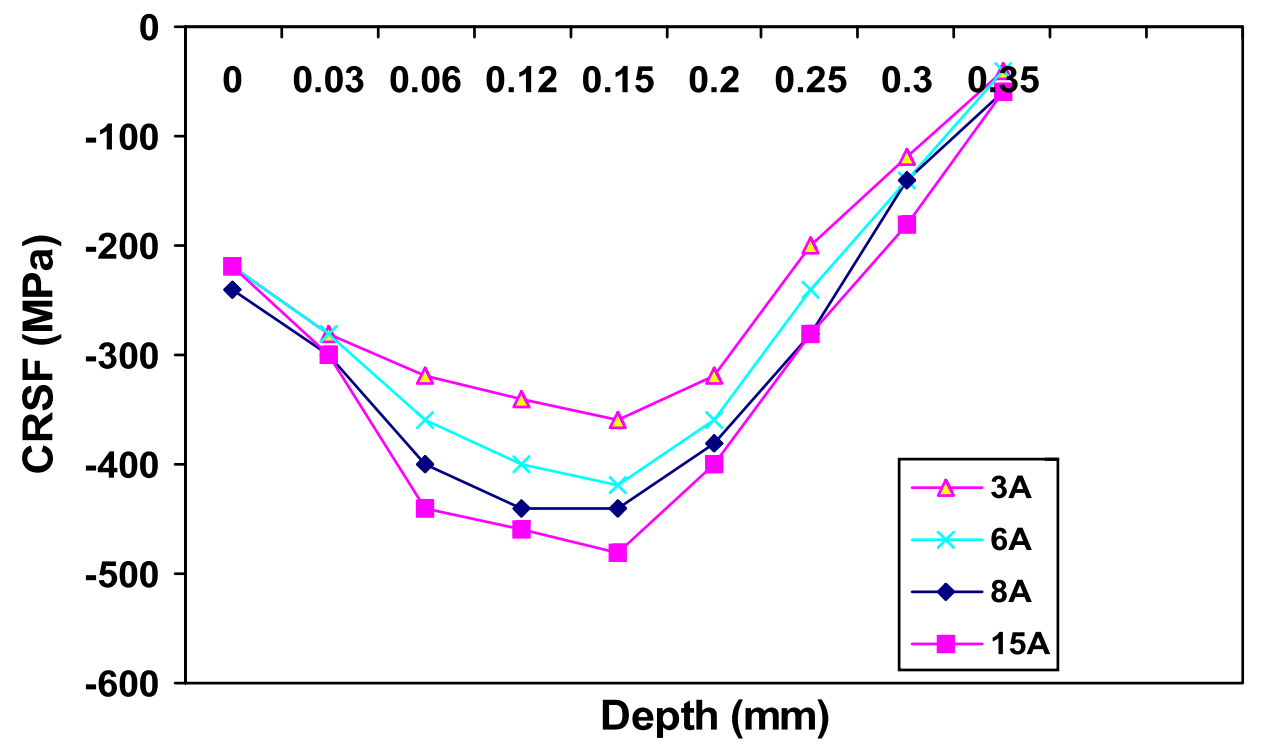

Figure 7. CRSF for various shot peening intensities

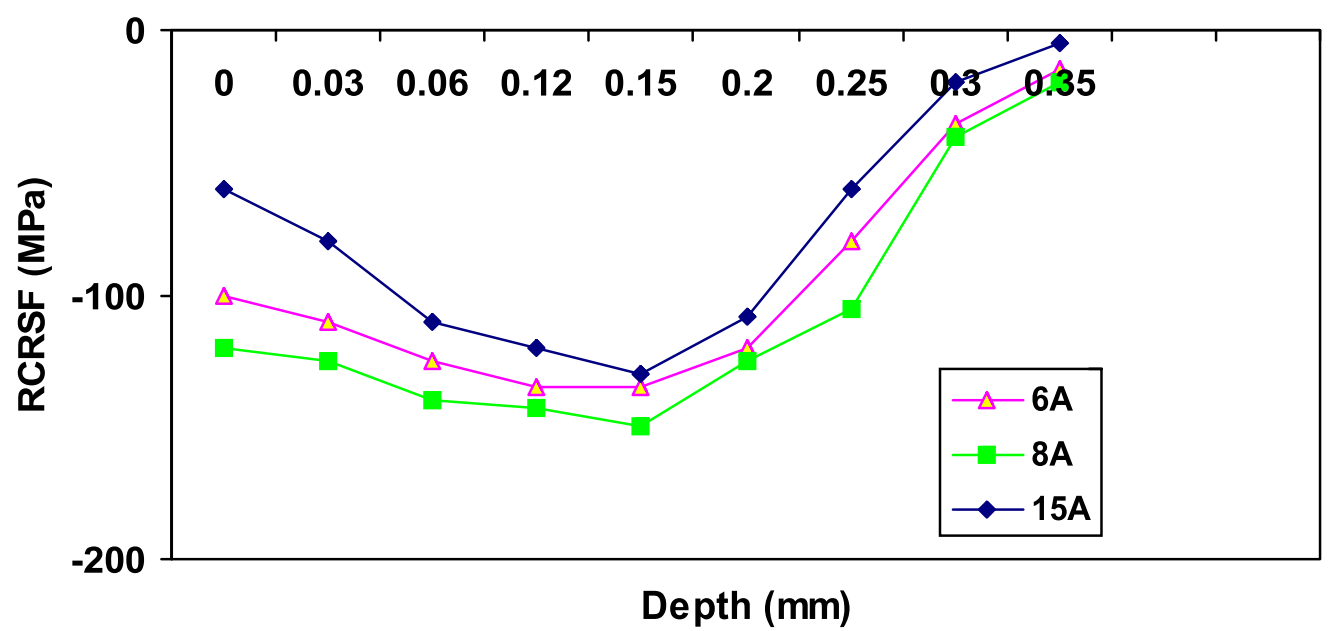

Figure 8. Relaxation of CRSF at different shot peening conditions

$1 \mathrm{~A}^{0}=10^{-8} \mathrm{~cm}, \mathrm{E}=$ Young's Modulus of the Material

The relaxation behaviour of compressive residual stresses is an essential problem for performance and life prediction of shot peened material and structure. The variation of CRSF at different depths for all the peening conditions is shown in Fig. 7. It is common to all of the materials that the shot peening induced 
compressive residual stress must be released during cyclic loading when the superimposed stress of residual and applied ones is beyond the static and cyclic yield strength. It is usually admitted that the benefit of shot peening is more pronounced for components under a high cyclic region. Figure 8 shows the relaxation of stress at different shot peenig intensities. Relaxed compressive residual stress field is also measured by X-ray diffraction.

\subsubsection{Exact Reduction in Weight}

The compressive residual stress generated on upper surface due to shot peening protects the part against tensile service load. Note that the sign of residual stress is important because if the part were reverse loaded in service to the point of yielding, it would relieve beneficial compressive stress and compromise the part life. The $\mathrm{S}_{\mathrm{sp}}$ in the component is given as:

$$
\mathrm{S}_{\mathrm{sp}}=\frac{S y+C R S F}{F O S}
$$

FOS has been applied on CRSF because of measurement error, wear of surface and variation in shot size.

Compressive residual stress induced by shot peening varies with cyclic loading due to relaxation of CRSF. Relaxation of CRSF is due to micro yielding and depends upon ductility of the material, number of cycles and stress applied. Therefore, the $\mathrm{S}_{\mathrm{sp}} /$ taking into account the relaxation of CRSF is stated as:

$$
\mathrm{S}_{\mathrm{sp}}^{\prime}=\frac{S y+R C R S F}{F O S}
$$

The CRSF should be added to yield stress for static loading and RCRSF should be added to yield stress for fatigue loading.

Aggarwal et al. 2006 illustrated that the results of EN45A spring steel specimens and heavy leaf springs used in commercial vehicles, differ from each other. During the present analysis, it is assumed that while working with simple AISI 304 stainless steel leaf springs, results are slightly lower than specimen results and it can be accommodated in factor of safety during fatigue design. A factor of safety 1.6 was chosen from the Eq. (6). The variations of the following eight, measure the factor of safety:

a) Contribution due to material properties $\left(\mathrm{FS}_{\mathrm{M}}\right)$. b) Contributions due to incomplete knowledge of load / stress $\left(\mathrm{FS}_{\mathrm{S}}\right)$.

c) Contribution due to geometry resulting from tolerance $\left(\mathrm{FS}_{\mathrm{G}}\right)$.

d) Contribution due to accuracy of failure analysis and the confidence one has put on them $\left(\mathrm{FS}_{\mathrm{FA}}\right)$.

e) Contribution because of reliability desired $\left(\mathrm{FS}_{\mathrm{R}}\right)$.

f) Contribution because of environment $\left(\mathrm{FS}_{\mathrm{E}}\right)$.

g) Factor to consider danger to personnel $\left(\mathrm{FS}_{\mathrm{D}}\right)$.

h) Factor to consider economic impact $\left(\mathrm{FS}_{\mathrm{El}}\right)$.

$$
\begin{aligned}
& \mathrm{FOS}=\mathrm{FS}_{\mathrm{M}} \text { X FS } \mathrm{SFF}_{\mathrm{G}} \times \mathrm{FS}_{\mathrm{FA}} \times \mathrm{FS}_{\mathrm{R}} \mathrm{XFS_{ \textrm {E } }} \\
& \mathrm{XFS}_{\mathrm{D}} \mathrm{XFS_{ \textrm {E } 1 }}
\end{aligned}
$$

The effect of shot peening intensity on fatigue design of semi-elliptical leaf spring with dimensions: $\mathrm{P}=300 \mathrm{~N}, \mathrm{~L}=425 \mathrm{~mm}, \mathrm{t}=40 \mathrm{~mm}, \mathrm{~b}=60 \mathrm{~mm}, \mathrm{n}=6, \mathrm{~L}_{\text {т }}$ $=3.635 \mathrm{~m}$ and $\rho=7900 \mathrm{Kg} / \mathrm{m}^{3}$, is shown in Table 5 .

Bending stress for leaf springs $\left(\sigma_{\mathrm{b}}\right)$ was calculated using (Aaron 1985),

$\sigma_{\mathrm{b}}=6 \mathrm{PL} / \mathrm{nbt}^{2}$

Weight of leaf spring was calculated as,

$\mathrm{W}=\mathrm{L}_{\mathrm{T}} \mathrm{bt} \mathrm{X} \rho$

\section{Conclusions}

The following conclusions were drawn from the above discussion:

1) The CRSF relaxes due to fatigue loading. Relaxed compressive residual stress field (RCRSF) due to fatigue loading must be considered for reliable fatigue design of stainless steel AISI 304 leaf springs.

2) The weight reduction is higher in case of static loading but it is lesser in case of dynamic loading. It may be observed that there is a $10-20 \%$ weight reduction at optimum shot peening intensity. The designer must include the effect of shot peening, in calculation if he wants to remain competitive.

3) Shot peening is also found to be effective process for controlling mechanical properties such as damping factor, hardness and fatigue life in metallic surfaces. 
Table 5. Effect of almen intensities of fatigue design

\begin{tabular}{|c|c|c|c|c|c|c|c|}
\hline \multirow[t]{2}{*}{ SNo. } & \multicolumn{2}{|c|}{ Parameter } & \multirow{2}{*}{$\begin{array}{c}\text { Base } \\
\text { Material }\end{array}$} & \multicolumn{4}{|c|}{ Shot peening int en sities } \\
\hline & & & & $\mathbf{3 A}$ & $6 \mathrm{~A}$ & $\mathbf{8 A}$ & $15 \mathrm{~A}$ \\
\hline \multirow{3}{*}{1} & \multirow{3}{*}{$\begin{array}{c}\text { Static } \\
\text { Loading }\end{array}$} & $\begin{array}{l}\text { Permissible } \\
\text { Stress (MPa) }\end{array}$ & 132 & 181.25 & 193.75 & 206.25 & 168.75 \\
\hline & & $\begin{array}{l}\text { Calculated t } \\
(\mathrm{mm})\end{array}$ & 4 & 3.42 & 3.31 & 3.21 & 3.54 \\
\hline & & $\begin{array}{c}\text { Weight of Leaf } \\
\text { Springs }(\mathrm{Kg})\end{array}$ & 6.89 & 5.89 & 5.70 & 5.53 & 6.09 \\
\hline \multirow{3}{*}{2} & \multirow{3}{*}{$\begin{array}{l}\text { Dynamic } \\
\text { Loading }\end{array}$} & $\begin{array}{l}\text { Fatigue Strength } \\
\qquad(\mathrm{MPa})\end{array}$ & 176 & 191 & 202 & 212 & 209 \\
\hline & & $\begin{array}{l}\text { Calculated t } \\
(\mathrm{mm})\end{array}$ & 4.20 & 3.98 & 3.84 & 3.73 & 3.80 \\
\hline & & $\begin{array}{c}\text { Weight of Leaf } \\
\text { Springs (Kg) }\end{array}$ & 7.24 & 6.86 & 6.62 & 6.43 & 6.53 \\
\hline
\end{tabular}

\section{References}

Aaron, D., 1985, "Machine Design," 3 ${ }^{\text {rd }}$ Ed, Macmillan Publishing Co. USA, pp 750-757.

Aggarwal, M.L, Khan, R.A. and Agrawal, V.P, 2005, "Influence of Shot Peening Intensity of Fatigue Design Reliability of 65Si7 Spring Steel," Indian Journal of Engg. \& Materials Science, Vol. 12(6), pp 515-520.

Aggarwal, M.L, Agrawal, V.P. and Khan, R.A., 2006, "A Stress Approach Model for Predicting Fatigue Life of EN45A Spring Steel," Int. J. Fatigue, Elsevier Publication, Vol. 28(12), pp. 1845-53.

Aggarwal, M.L., 2008, "Shot Peened High Nitrogen Austenitic Stainless Steel: An Alternate to Ni Rich Austenitic Stainless Steel for Medical Applications," Int. J. of Materials and Product Technology, (Accepted).

Devdutt and Aggarwal M.L., 2006, "Trends and Advances in Austenitic Stainless Steel," National Conf. on Trends and Advances in Mech. Engg., YMCAIE Faridabad, India, p. 470.

Gao, Y.K., Yin, Y.F. and Yao, M., 2003, "Effects of Shot Peening on Fatigue Properties of 0Cr13Ni8Mo2Al Steel," Materials Science and Technology. Vol.19(3), pp. 372-374.

GAO Yukui., 2004, "Microstructure Changes and
Residual Stresses of each Phase caused by Shot Peening in 304 Austenitic Stainless Steel," Journal of Aeronautical Materials. Vol. 24(4), pp. 18-21.

Meriam, J.L. and Kraige, L.G., 2002, "Engineering Mechanics," Vol. 2, 5th Ed. (John Wiley \& Sons, Inc., Singapore), pp. 593-600.

Mitsubayashi, M., Miyata T. and Aihara, H., 1995, "Prediction of Improvement in Fatigue Strength by Shot Peening and Selection of Most Effective Peening Condition," Trans. Jpn Soc. Mech. Eng. Ser A, Vol. 61, pp. 1172-1178.

Pandey, R.K. and Deshmukh, M.N., 2001, "Shot Peening and its Effect on Fatigue Life of Engineering Components," Int. Conf. on Shot Peening and Shot Blasting, pp. 1-20.

SAE Annual Book of ASTM Standards Part - 10, 1977, pp. 536-554.

Schijve, J., 2003, "Fatigue of Structures and Materials in the 20th Century and the State of the Art," Int. J. of Fatigue, Vol. 25(8), pp. 679-700.

Shaw, B.A., Aylott, C., Hara, P.O. and Brimble, K., 2003, "The Role of Residual Stress on the Fatigue Strength of High Performance Gearing," Int. J. of Fatigue, Vol. 25, pp. 1279-1283.

Sharma, M.C., 2001, "Shot Peening and Blasting," Int. Conf. on Shot Peening and Sand Blasting, pp. 190-195. 